\title{
Hydraulic Resistance Induced by Deposition of Sediment in Porous Medium
}

\author{
By Fu-Chun Wu' and Hung-Tzu Huang ${ }^{2}$
}

\begin{abstract}
The deposition of the instantaneously released sediment into a gravel matrix and the hydraulic resistance induced by the rapid siltation are investigated herein. The experimental results reveal that the depositional patterns of the sediment are governed by the gravel-sediment size ratio, the amount of sediment released, and the seepage flowrate. The observations also indicate that the stable stage of sediment deposition is reached shortly after the occurrence of sudden slump. A regression relation is developed to quantify the stable-stage hydraulic resistance with the major governing factors. Given the hydraulic resistance, one can use the siltation equation to evaluate the hydraulic conductivity of the silted porous medium. With such information, planning of the engineering alternatives to meet the seepage flow requirements is made possible.
\end{abstract}

\section{INTRODUCTION}

The deposition and accumulation of fine sediments in gravel-bed streams may affect the ground-water recharge and the benthic ecosystem (ASCE 1992; Schälchli 1995). This can occur as a slow, insidious process with the continuing deposition of small quantities of sediments or be triggered as a rapid, almost catastrophic, event, exemplified by a sudden slump or landslide (Reiser et al. 1989). The gradual siltation process of riverbeds has been intensively investigated by Schälchli (1995), and a quantitative relationship describing the reduction of hydraulic conductivity with time has been proposed as follows:

$$
K(t)=\frac{g L}{v \sqrt{\beta^{2}+\frac{2 g \Delta h}{v} r C t}}
$$

where $K(t)=$ hydraulic conductivity of bed material after time $t ; L=$ seepage length; $\beta=$ hydraulic resistance of unsilted riverbed $=g L / K_{0} v ; K_{0}=$ hydraulic conductivity of unsilted bed material; $g=$ gravitational acceleration; $v=$ kinematic viscosity of water; $\Delta h=$ pressure head; $r=$ specific hydraulic resistance; and $C=$ concentration of suspended load (by weight). The specific hydraulic resistance $r$ varies as a function of the uniformity of bed material, Reynolds number, hydraulic gradient of infiltrating water, and bed shear stress (Schälchli 1995). It is pointed out that the $r$ values for the siltation process in rivers lie in the range between $2 \times 10^{10}$ and $2 \times 10^{12} \mathrm{~m} / \mathrm{kg}$. Eq. (1) has been developed to evaluate the variation of the hydraulic conductivity of a riverbed for the slow siltation process; however, the deposition of a sudden slump of sediments and the consequential hydraulic resistance induced by the rapid siltation has rarely been addressed previously (Schälchli 1995). Since the mechanisms of these two siltation processes are fairly different and the physical parameters used to define the systems are not identical, there is a need for a quantitative relationship that models the rapid siltation process. The objective of this experimental study is to investigate the deposition of instantaneously released sediments in a porous medium and the hydraulic resistance induced by such a rapid siltation process.

${ }^{1}$ Asst. Prof., Dept. of Agric. Engrg. and Hydrotech Res. Inst., National Taiwan Univ., Taipei, Taiwan, R.O.C.

${ }^{2}$ Grad. Res. Asst., Inst. of Envir. Engrg., Nat. Taiwan Univ., Taipei, Taiwan, R.O.C.

Note. Discussion open until December 1, 2000. To extend the closing date one month, a written request must be filed with the ASCE Manager of Journals. The manuscript for this technical note was submitted for review and possible publication on November 8, 1994. This technical note is part of the Journal of Hydraulic Engineering, Vol. 126, No. 7, July, 2000. CASCE, ISSN 0733-9429/00/0007-0547-0551/\$8.00 + \$.50 per page. Technical Note No. 9564.

\section{EXPERIMENTS}

The laboratory experiments were conducted with a $25 \times 25$ cm column filter (shown in Fig. 1). The gravel filter is $30 \mathrm{~cm}$ in length (i.e., the seepage length $L=30 \mathrm{~cm}$ ). The experimental setup consists of a column filter, a sand supplier, and a recirculating water supply system. The valves and flowmeter in the system allow us to maintain a constant seepage flow. For each trial, a predetermined quantity of sand was instantaneously released to the system and the mixture infiltrated into the gravels with an instantaneous concentration $C_{i}$. After a sufficient period of time (usually within a few minutes), sediment deposition reached a stable stage due to the clogging effect. Flow was then terminated, and the water in the system was drained. The sand remaining atop the filter surface and the sand accumulating within the gravel filter were sampled and their quantities (designated as $m_{0}$ and $m$ in Fig. 1, respectively) were measured, where $m$ is the sum of the sediment deposits taken from the six 5-cm-thick layers of the gravel filter. A review of previous studies (e.g., Behnke 1969; Sakthivadivel and Einstein 1970; Cunningham et al. 1987) suggests that three major factors govern the siltation of porous media; they are the grain sizes of sediment and gravel, sediment concentration, and seepage flow velocity. The gravel/

$$
\text { Time }=t_{0} \quad \text { Time }=t
$$

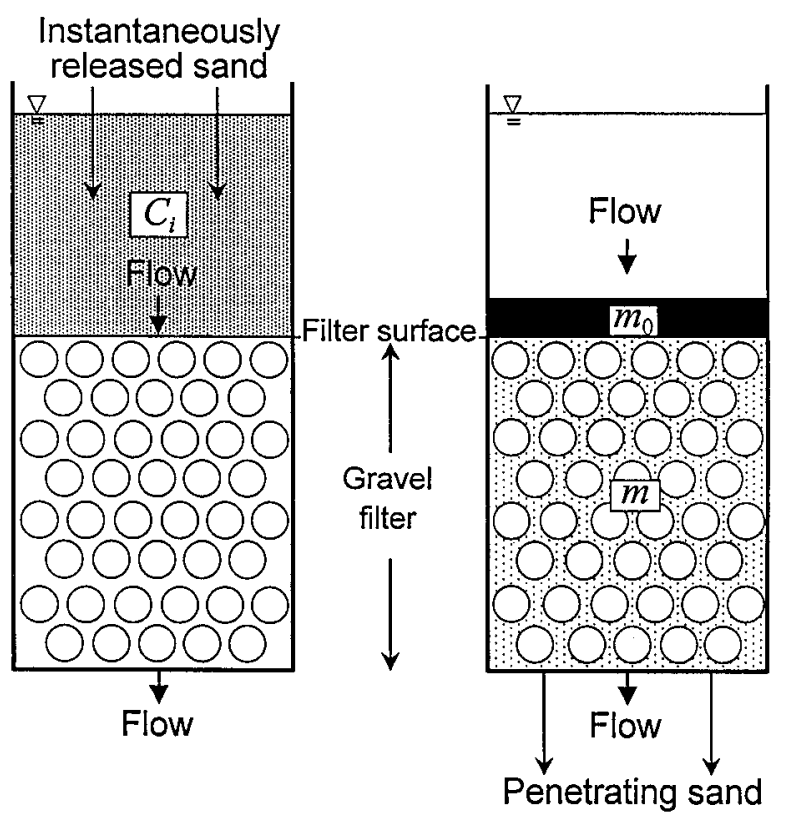

FIG. 1. Sketch of Experimental Setup Showing Deposition of Instantaneously Released Sediment into Gravel Filter 
TABLE 1. Characteristic Sizes and Hydraulic Conductivity of Gravels Tested

\begin{tabular}{|c|c|c|c|}
\hline $\begin{array}{c}\text { Gravel type } \\
\text { (1) }\end{array}$ & $\begin{array}{c}D_{15} \\
(\mathrm{~mm}) \\
(2)\end{array}$ & $\begin{array}{c}D_{50} \\
(\mathrm{~mm}) \\
(3)\end{array}$ & $\begin{array}{c}K_{0} \\
(\mathrm{~cm} / \mathrm{s}) \\
(4)\end{array}$ \\
\hline $\begin{array}{l}\text { Type A } \\
\text { Type B }\end{array}$ & $\begin{array}{l}6.7 \\
5.1\end{array}$ & $\begin{array}{l}7.5 \\
5.8\end{array}$ & $\begin{array}{l}2.66 \\
1.61\end{array}$ \\
\hline
\end{tabular}

TABLE 2. Characteristic Sizes of Sands Tested

\begin{tabular}{c|c|c}
\hline \hline $\begin{array}{c}\text { Sand type } \\
(1)\end{array}$ & $\begin{array}{c}d_{50} \\
(\mathrm{~mm})\end{array}$ & $\begin{array}{c}d_{85} \\
(\mathrm{~mm}) \\
(3)\end{array}$ \\
\hline$\# 1 \mathrm{C}$ & $(2)$ & 1.10 \\
$\# 30$ & 0.87 & 0.55 \\
$\# 60$ & 0.42 & 0.41 \\
\hline \hline
\end{tabular}

sediment sizes can be represented by a single parameter, i.e., the grain size ratio $R_{S}$, defined as $\left(D_{15}\right.$ of gravel $) /\left(d_{85}\right.$ of sediment) (Sowers and Sowers 1970; Sherard et al. 1984). For this study, two types of rounded gravel (types A and B) and three kinds of uniformly graded sand (\#1C, \#30, and \#60) were used in the experiments. The characteristic sizes of these materials and the hydraulic conductivity $\left(K_{0}\right)$ of the gravels are given in Tables 1 and 2, where the $K_{0}$ values are calculated by Kozeny equation (see Schälchli 1995) using the grain-size distributions of the gravels. Five gravel-sand combinations were used, namely, A-1C, A-30, A-60, B-30, and B-60. The $R_{S}$ values for these combinations ranged from 6.1 to 16.3 . The porosity of the packed gravels was 0.4 ; the specific gravity of the sand was 2.65; and the average water temperature was $16^{\circ} \mathrm{C}$ (for which $\left.v=1.14 \times 10^{-6} \mathrm{~m}^{2} / \mathrm{s}\right)$. The testing conditions covered wide ranges of seepage flowrate $\left(1 \times 10^{-3}-6 \times 10^{-3} \mathrm{cms} /\right.$ $\left.\mathrm{m}^{2}\right)$ and instantaneous sediment concentration $(80-1,280 \mathrm{~kg} /$ $\mathrm{m}^{3}$ ). A total of 40 experimental runs were performed with various testing conditions. More details of the experiments and a summary of the results are available in Wu and Shen (1999).

\section{THEORETICAL BACKGROUND}

\section{Relationship between Hydraulic Conductivity and Sediment Deposit}

Sakthivadivel (1966) compared several hydraulic models quantifying the resistance induced by the sediments accumulated in a porous medium. According to a series of laboratory experiments, he concluded that the hydraulic radius model leads to the most satisfactory results. Based on such a model, the first writer (Wu 1993) presented the formulation of a relationship describing the variation of hydraulic conductivity with the sediment deposit, i.e.

$$
\frac{K(\sigma)}{K_{0}}=f(\sigma)=(5.625) \frac{[0.4-(5 \sigma / 3)]^{3}}{[0.6+(5 \sigma / 3)]^{2}}+\left(R_{15}\right)^{2}\left(\frac{\sigma}{0.24}\right)
$$

where $\sigma=$ specific deposit $=($ volume of sediment deposit $) /$ (bulk volume of porous medium); $K(\sigma)=$ hydraulic conductivity of the silted porous medium; and $R_{15}=\left(d_{15}\right.$ of sediment $) /$ ( $D_{15}$ of gravels). The first and second terms on the right-hand side of (2) are related to the resistance for the flows through effective pores and the interstices between sediment deposit, respectively. For a given $R_{15}$, one can use (2) to evaluate the hydraulic conductivity corresponding to a quantity of sediment deposit.

\section{Modified Siltation Equation for Instantaneously Released Sediment}

For the gravel matrix receiving the instantaneously released sediments, the term of $r C t$ in (1) can be replaced by $r^{\prime} \sigma_{s}$ due to the nature of the fast depositional process, where $r^{\prime}$ is the specific hydraulic resistance induced by rapid siltation, and $\sigma_{s}$ is the stable-stage specific deposit. Accordingly, (1) can be expressed as the following:

$$
K\left(\sigma_{s}\right)=\frac{g L}{v \sqrt{\beta^{2}+\frac{2 g \Delta h}{v} r^{\prime} \sigma_{s}}}
$$

Rewriting (2) as $K\left(\sigma_{s}\right)=K_{0} \cdot f\left(\sigma_{s}\right)$ and substituting this into (3) yields

$$
r^{\prime} \sigma_{s}=\frac{g L^{2}}{2 \Delta h \nu K_{0}^{2}} \cdot\left[\frac{1}{f^{2}\left(\sigma_{s}\right)}-1\right]
$$

Employing the definitions of $\beta$ and Darcy velocity [i.e., the seepage flowrate per unit area $q=K\left(\sigma_{s}\right) \cdot i$, where the hydraulic gradient $i=\Delta h / L]$, one can further modify (4) as

$$
r^{\prime} \sigma_{s}=\frac{\beta}{2 q} \cdot Y\left(\sigma_{s}\right)
$$

where $Y\left(\sigma_{s}\right)=1 / f\left(\sigma_{s}\right)-f\left(\sigma_{s}\right)$, whose value can be determined through (2). Given the required input data (i.e., the physically measured seepage flowrate $q$ and sediment deposit $\sigma_{s}$ ), one can use (5) to evaluate the stable-stage hydraulic resistance induced by the rapid siltation.

\section{RESULTS AND DISCUSSION}

\section{Deposition of Instantaneously Released Sediment}

The purpose of this section is to illustrate the variabilities of sediment deposition with the major governing factors (which include the grain sizes of gravel and sand, the quantity of instantaneous sediment release, and the seepage flowrate). The predictive relationships for the distributions of sediment deposit that correspond to various physical conditions have been developed from a complex stochastic approach (Wu 1993; Wu and Shen 1999); hence, they are not to be discussed herein. Instead, some insights into the depositional features of the instantaneously released sediments are presented. The cumulative probability distributions of the sediment deposit along the depth of the gravel filter are shown in Figs. 2-4. In Fig. 2, the four solid lines (for different $R_{S}$ ) represent the distributions of sediment deposit at the stable stage under the 2F2 condition (i.e., instantaneous release of $2-\mathrm{kg}$ sand with a seepage flowrate of $\left.2 \times 10^{-3} \mathrm{cms} / \mathrm{m}^{2}\right)$. For $R_{S}=12.2$, the

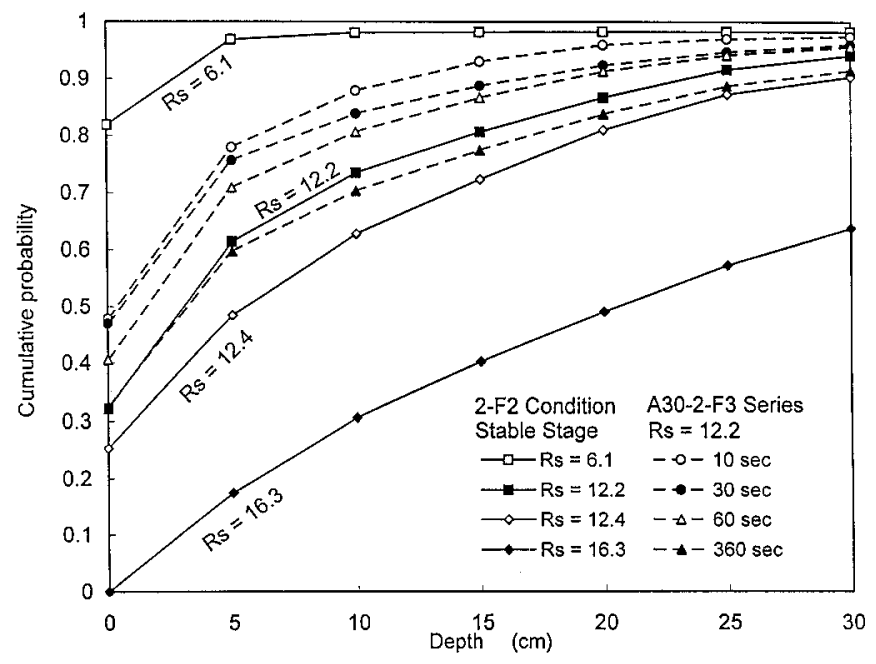

FIG. 2. Cumulative Probability Distributions of Sediment Deposit for Various Gravel-Sediment Size Ratios and Running Periods 


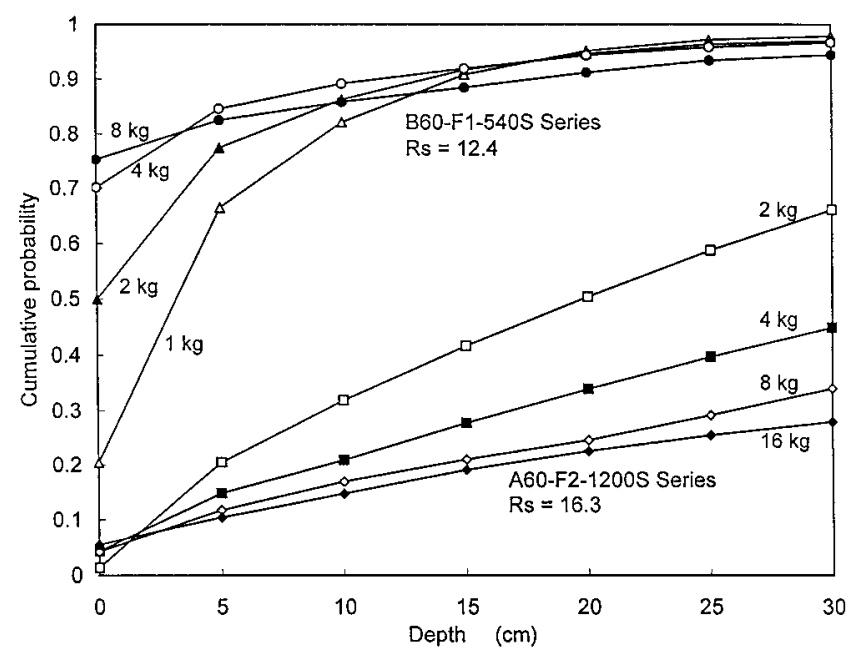

FIG. 3. Cumulative Probability Distributions of Sediment Deposit for Various Quantities of Input Sediment

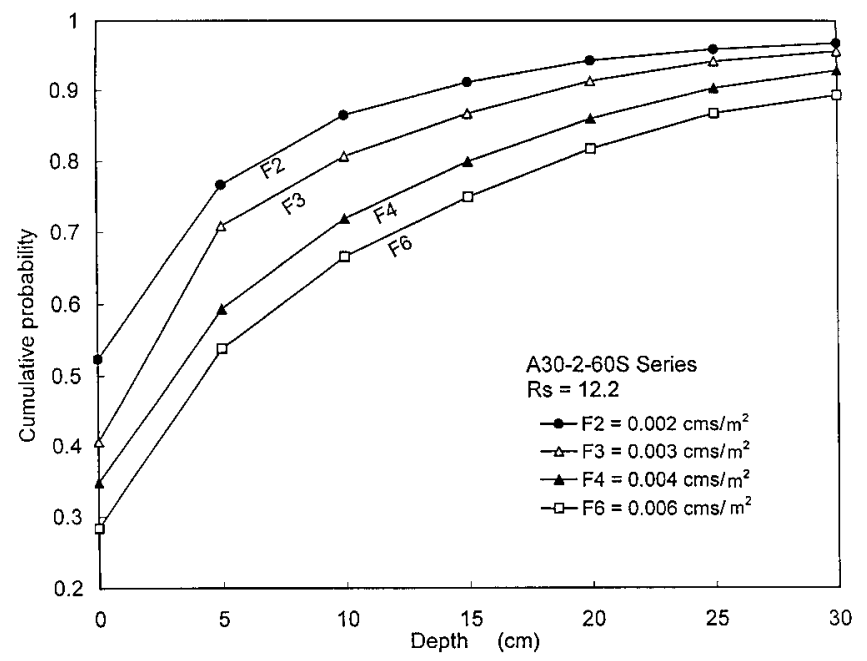

FIG. 4. Cumulative Probability Distributions of Sediment Deposit for Various Seepage Flowrates

evolution of sediment deposition under the 2-F3 condition is also illustrated by the four dashed lines. From the cumulative distribution curves of various running periods $(10,30,60$, and 360 seconds, respectively), one may find that sediment deposition is increasing at the beginning of intrusion but then reaches a stable stage in a period of time that is on the order of several minutes. The stable stage is a result of either surface clogging or deep deposition of the sediment. As such a stage is reached, the captured particles remain stable in the pore space and inhibit further infiltration of sediment (Sakthivadivel and Einstein 1970). The distribution curves also show that the quantity of sediment deposit decreases with the depth. However, in contrast to the nearly constant amount of sand that was trapped in the top layer (for depth $=0-5 \mathrm{~cm}$ ), the quantity of sediment deposited to the bottom layer (for depth $=25-30$ $\mathrm{cm}$ ) increased from 0.4 to $2.8 \%$ in a period of 6 minutes or so.

For smaller $R_{S}$ values (i.e., for coarser sand relative to gravel), most of the input sand was deposited at the surface and top layer of the filter. As the size ratio becomes greater, the sediment deposit tends to be more uniformly distributed along the depth of the filter. On the other hand, when $R_{S}$ is greater, a larger portion of the input sand penetrated through the filter because of the lower efficiency of sediment removal. Obviously, the size ratio is the dominating factor for the distribution of sediment deposit. Sakthivadivel and Einstein
(1970) reported that less than $1 \%$ of the total pore volume was occupied by the sediment deposit when the size ratio is larger than 15. Sakthivadivel (1966) claimed that the dominant filtration mechanisms for the coarser particles are bridging and straining, whereas Herzig et al. (1970) stated that the finer particles are mainly captured by sedimentation and interception in the still zones. Sakthivadivel (1969) further pointed out that the probability of bridging a pore is practically zero when the size ratios are greater than 24 . However, due to the limitations of the testing materials, the data do not allow the writers to establish guidelines for distinguishing the mechanisms of rapid siltation by the size ratio.

The variability of sediment deposition with the quantity of input sand is shown in Fig. 3, where the two groups of cumulative distribution curves are for $R_{S}=12.4$ and 16.3, respectively. These curves reveal that both the relative and absolute quantities of sand remaining atop the filter surface and penetrating through the filter are positively correlated to the amount of input sediment. However, the depositional patterns are quite diverse for the two groups of curves. For the coarser sediment, the distributions mainly differ in the probabilities of surface deposition, whereas for the finer sediment, the main differences are in the probabilities of penetration. The removal efficiency of the filter is reduced when the quantity of input sediment increases.

The variability of sediment deposition with the seepage flowrate is shown in Fig. 4, where the four distribution curves are for the flowrates ranging from 0.002 to $0.006 \mathrm{cms} / \mathrm{m}^{2}$. These curves reveal the fact that the quantity of sediment infiltrating into the gravel matrix is increasing with the seepage flowrate. Cunningham et al. (1987) stated that the depositional process occurs as a result of gravitational settling enhanced by the hydraulic gradient. The stronger seepage force induced by the greater flow carries a larger quantity of sediment into the gravel matrix (although in the writers' experiments the maximum pore velocity is less than $30 \%$ of the particle-settling velocity). Sakthivadivel (1966) further claimed that the seepage flow strengthens the bridging between sand particles and thus increases the quantity of captured sediment; Rice (1974) also pointed out that the seepage flow accelerates the clogging of pores. On the other hand, due to the enhanced transport capability, the greater seepage flow reduces the efficiency of sediment removal. In Fig. 4, the distribution curves appear to be more parallel in the upper layers; this indicates that the quantities of sediment deposit in the upper layers are approximately identical for various seepage flowrates, while in the lower portion of the filter, greater seepage flow results in larger quantities of sediment deposit.

\section{Hydraulic Resistance Induced by Rapid Siltation}

The experimental data reveal that the $\sigma_{s}$ value (which represents the stable-stage specific deposit with respect to the bulk volume of the gravel filter) ranged from 0.006 to 0.07 . The calculation results from (5) indicate that $r^{\prime} \sigma_{s}$ varies in the range between $6 \times 10^{9}$ and $6 \times 10^{10} \mathrm{~s} / \mathrm{m}^{2}$, depending on the testing material and seepage flowrate. To investigate the variation of $r^{\prime} \sigma_{s}$ with the testing conditions, a regression analysis is performed. Three dimensionless variables are used to represent the major governing factors; these include the gravelsediment size ratio $R_{S}$, the dimensionless instantaneous concentration $I$, and the dimensionless seepage velocity $V$. The dimensionless concentration $I$ is defined as $C_{i} / \rho_{s}$, where $\rho_{s}$ is the density of sediment particle $\left(=2,650 \mathrm{~kg} / \mathrm{m}^{3}\right)$. The dimensionless seepage velocity $V$ is defined as $q / K_{0}$, which represents the hydraulic gradient (or alternatively, the pressure head available) for the infiltrating water. Applying the linearization method [or the Taylor series method; see Draper and Smith 


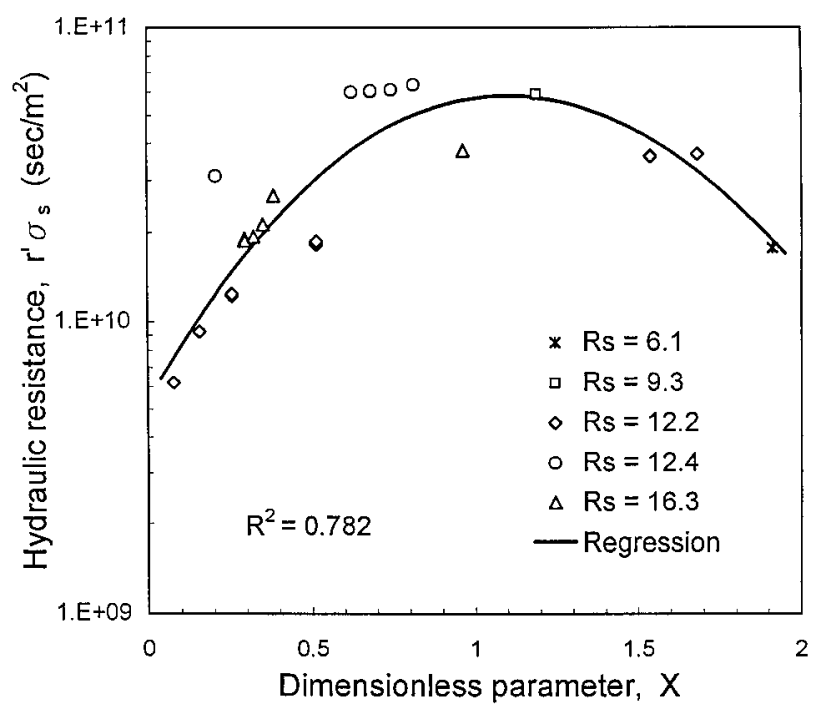

FIG. 5. Relationship between Stable-Stage Hydraulic Resistance and Dimensionless Parameter $\boldsymbol{X}\left(=\boldsymbol{R}_{S}^{-1.89} \boldsymbol{I}^{0.13} \boldsymbol{V}^{-1.71}\right)$

(1981)] on the experimental data leads to the following result, with the coefficient of determination $R^{2}=0.782$ :

$$
\begin{gathered}
r^{\prime} \sigma_{s}=\exp \left(0.13 X^{3}-2.26 X^{2}+4.49 X+22.41\right) \\
X=R_{S}^{-1.89} I^{0.13} V^{-1.71}
\end{gathered}
$$

where $r^{\prime} \sigma_{s}$ is in $\mathrm{s} / \mathrm{m}^{2}$. Eq. (6) indicates that the size ratio and the seepage velocity are approximately equally influential to the hydraulic resistance (to the -1.89 and -1.71 powers of $R_{S}$ and $V$, respectively), while the instantaneous sediment concentration has a relatively minor influence on $r^{\prime} \sigma_{s}$ (to the 0.13 power of $I$ ). The $r^{\prime} \sigma_{s}-X$ relationship is shown in Fig. 5, where the dimensionless parameter $X$ lies in the range between 0 and 2 for our experiments, with the maximum $r^{\prime} \sigma_{s}$ occurring at $X=1.1$. The stable-stage hydraulic resistance $r^{\prime} \sigma_{s}$ is a characteristic resulting from the rapid siltation process that depends on the gravel/sediment size distributions, instantaneous sediment concentration, and hydraulic gradient for seepage flow. For the deposition process associated with the instantaneous sediment release, the stable stage is commonly reached in a very short period of time. Hence, $K\left(\sigma_{s}\right)$ can be used to represent the resultant hydraulic conductivity after the occurrence of sudden slump and deposition of sediment. By using (6) and (3) to evaluate $K\left(\sigma_{s}\right)$, one can eliminate the difficulty of estimating $\sigma_{s}$ that would have been encountered if, otherwise, (2) were used. However, the empirical relation proposed in (6) has its limitations. Since the regression is based on the experimental data, the applicability of (6) outside the range of tests is not warranted (applicable range: $6<R_{S}<16,0.03<$ $I<0.5,0.04<V<0.2)$. Given $K\left(\sigma_{s}\right)$, it is possible for the water-resources engineer to properly adjust the hydraulic gradient (or pressure head) and achieve the seepage flowrate required for maintaining the efficient ground-water recharge, or the healthy spawning habitat and benthic ecosystem.

\section{CONCLUSIONS}

This work presents the deposition of instantaneously released sediments in a gravel matrix and the hydraulic resistance induced by rapid siltation of the porous medium. The experimental results reveal that the gravel-sediment size ratio, the quantity of input sediment, and the seepage flowrate are the dominating factors that govern the depositional processes of the sudden slump. The stable stage of sediment deposition is generally reached in a fairly short period of time due to the clogging effect. The stable-stage hydraulic resistance $r^{\prime} \sigma_{s}$ that varies as a function of the major governing factors is a characteristic resulting from the rapid siltation. The hydraulic resistance $r^{\prime} \sigma_{s}$ can be evaluated with the regression relationship proposed in (6); then, the corresponding hydraulic conductivity $K\left(\sigma_{s}\right)$ can be determined with the modified siltation equation given in (3). Based on the estimated hydraulic conductivity, it is possible to make proper engineering adjustments to meet the seepage flow requirements for various environmental and ecological purposes.

\section{ACKNOWLEDGMENTS}

This study was partially supported by the National Science Council of the Republic of China. The writers appreciate H. W. Shen for helpful discussions. The constructive suggestions from the ASCE reviewers and the editor are acknowledged.

\section{APPENDIX I. REFERENCES}

ASCE Task Committee on Sediment Transport and Aquatic Habitats, Sedimentation Committee. (1992). "Sediment and aquatic habitat in river systems." J. Hydr. Engrg., ASCE, 118(5), 669-687.

Behnke, J. J. (1969). "Clogging in surface spreading operations for artificial ground-water recharge." Water Resour. Res., 5(4), 870-876.

Cunningham, A. B., Anderson, C. J., and Bouwer, H. (1987). "Effects of sediment-laden flow on channel bed clogging." J. Irrig. and Drain. Engrg., ASCE, 113(1), 106-118.

Draper, N. R., and Smith, H. (1981). Applied regression analysis. Wiley, New York.

Herzig, J. P., Leclerc, D. M., and Le Goff, P. (1970). "Flow of suspensions through porous media-application to deep filtration." Indust. and Engrg. Chem., 62(5), 8-35.

Reiser, D. W., Ramey, M. P., and Wesche, T. A. (1989). "Chapter 4: Flushing flows." Alternatives in regulated river management, J. A. Gore and G. E. Petts, eds., CRC Press, Boca Raton, Fla., 91-135.

Rice, R. C. (1974). "Soil clogging during infiltration of secondary effluent." J. Water Pollution Control Fed., 46(4), 708-716.

Sakthivadivel, R. (1966). "Theory and mechanism of filtration of noncolloidal fines through a porous medium." Tech. Rep. HEL 15-5, Hydr. Engrg. Lab., University of California, Berkeley, Calif.

Sakthivadivel, R. (1969). "Clogging of a granular porous medium by sediment." Tech. Rep. HEL 15-7, Hydr. Engrg. Lab., University of California, Berkeley, Calif.

Sakthivadivel, R., and Einstein, H. A. (1970). "Clogging of porous column of spheres by sediment." J. Hydr. Div., ASCE, 96(2), 461-472.

Schälchli, U. (1995). "Basic equations for siltation of river beds." $J$. Hydr. Engrg., ASCE, 121(3), 274-287.

Sherard, J. L., Dunnigan, L. P., and Talbot, J. R. (1984). "Basic properties of sand and gravel filters." J. Geotech. Engrg., ASCE, 110(6), 684700 .

Sowers, G. B., and Sowers, G. F. (1970). Introductory soil mechanics and foundations. Macmillan, New York.

Wu, F.-C. (1993). "Stochastic modeling of sediment intrusion into gravel beds." PhD thesis, University of California, Berkeley, Calif.

Wu, F.-C., and Shen, H. W. (1999). "First-order estimation of stochastic parameters of a sediment transport model." J. Hydr. Res., Delft, The Netherlands, 37(2), 213-227.

\section{APPENDIX II. NOTATION}

The following symbols are used in this paper:

$C=$ concentration of suspended load;

$C_{i}=$ instantaneous sediment concentration;

$D_{15}, D_{50}=$ grain sizes of gravel of which 15 and $50 \%$ are finer;

$d_{50}, d_{85}=$ particle sizes of sediment of which 50 and $85 \%$ are finer;

$g=$ gravitational acceleration;

$I=$ dimensionless sediment concentration $=C_{i} / \rho_{s}$;

$i=$ hydraulic gradient $=\Delta h / L$;

$K(t)=$ hydraulic conductivity of bed material after time $t$;

$K(\sigma)=$ hydraulic conductivity of silted porous medium;

$K_{0}=$ hydraulic conductivity of unsilted bed material;

$L=$ seepage length;

$m=$ quantity of sediment deposit within gravel filter;

$m_{0}=$ quantity of sediment deposit on surface of gravel filter; 
$q=$ seepage flowrate per unit area;

$R_{S}=$ size ratio defined as $D_{15} / d_{85}$;

$R_{15}=$ size ratio defined as $d_{15} / D_{15}$;

$r=$ specific hydraulic resistance;

$r^{\prime}=$ specific hydraulic resistance induced by rapid siltation;

$V=$ dimensionless seepage velocity $=q / K_{0}$;
$X=$ dimensionless parameter in (6);

$\beta=$ hydraulic resistance of unsilted riverbed $=g L / K_{0} \nu$;

$\Delta h=$ pressure head;

$v=$ kinematic viscosity of water;

$\rho_{s}=$ density of sediment particle;

$\sigma=$ specific deposit;

$\sigma_{s}=$ stable-stage specific deposit. 